\title{
Zinc Oxide Nanoparticles for Removal of Arsenic from Water
}

\author{
Merghani M. Hassan, N. K. Devaraj, W. W. Wen, A.S.M Mukter-Uz-Zaman
}

\begin{abstract}
Removal of arsenate, As(V) from water was achieved using zinc oxide nanoparticles. The nanoparticles were synthesised from zinc acetate dihydrate and sodium hydroxide (NaOH) using the wet chemical sol-gel method. Different synthesis parameters were explored; including different ratios of $\mathrm{Zn:NaOH}$ and calcination temperatures. The synthesised samples were subsequently characterised and tested to investigate the adsorption capabilities of $\mathrm{ZnO}$ towards $\mathrm{As}(\mathrm{V})$. The colourimetric approach was utilised to analyse the samples' performance. The particles had a relatively large average size as tested by the nanoparticle size analyser and the X-Ray Diffraction (XRD) characterisation of the samples confirmed the formation of $\mathrm{ZnO}$. The peaks were narrow with high intensity, which indicates a larger crystal size and stable crystallinity. The samples showed a linear trend of increased adsorption capacity with the contact time. However, as indicated by the XRD and nanoparticle size analyser results, the particles had agglomerated and this has caused the total surface area to shrink. In summary, $\mathrm{ZnO}$ nanoparticles were successfully synthesised and were successful in adsorbing $A s(V)$ with different percentages for each sample. The adsorption trend was clear with respect to the changing parameters.
\end{abstract}

Index Terms: arsenic, heavy metals, nanoparticles, water, Zinc Oxide.

\section{INTRODUCTION}

Water plays a vital role in sustaining life, it impacts on all aspects of all humans' life including but not limited to; physical and mental health, nutrition, energy, economy, and politics [1].

Release of arsenic (As) into the environment occurs naturally through the weathering and erosion of sulphide-minerals [2]. It is estimated that $25 \%$ of arsenic emissions into the atmosphere are due to natural sources and the remaining $75 \%$ is a result of industrial activities, where the majority of the arsenic ends up in the soil and the oceans [3]. Arsenic exposure can cause cancer in any organic system as indicated by many studies and also has non-cancerous effects in humans. These include gangrene, abnormalities in skin colouration and thickening, cardiovascular and gastrointestinal diseases [4]-[5].

This research provides a unique perspective on the applications of zinc oxide nanoparticles for the removal of heavy metals from water. Among few techniques of arsenic

Revised Manuscript Received on August 18, 2019

Merghani M. Hassan, Faculty of Engineering, Multimedia University, Cyberjaya, Malaysia.

N. K. Devaraj, Faculty of Engineering, Multimedia University, Cyberjaya, Malaysia.

W. W. Wen, Faculty of Engineering, Multimedia University, Cyberjaya, Malaysia.

A.S.M. Mukter-Uz-Zaman, Faculty of Engineering, Multimedia University, Cyberjaya, Malaysia. removal from water (adsorption, ion exchange, coagulation, membrane and filtration), adsorption technique's efficiency, low-cost, simplicity and the insignificant amount of by-products makes adsorption a favourable and interesting technique to explore.

\section{MATERIALS AND METHODOLOGY}

\section{A. Synthesis of $\mathrm{ZnO}$ nanoparticles}

Through sol-gel method the $\mathrm{ZnO}$ powder was obtained in a consecutive four-stage process: synthesis, decantation, drying, and calcination.

In the synthesis stage, the sol-gel technique was used due to its simplicity, low cost, modification versatility and utilization of several materials: zinc acetate dihydrate (EMSURE) $\quad(\mathrm{Zn}(\mathrm{CH} 3 \mathrm{COO}) 2.2 \mathrm{H} 2 \mathrm{O})$, sodium hydroxide $(\mathrm{NaOH}) \geq 98 \% \quad$ (Sigma Aldrich) and ethanol $98 \%$ (denatured).

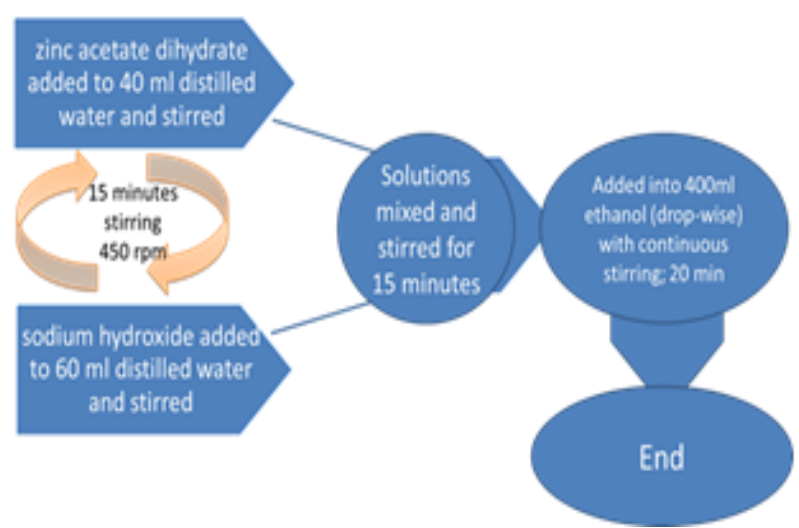

Fig 1. Synthesis of $\mathrm{ZnO}$ nanoparticles through sol-gel method

The sol-gel synthesis of $\mathrm{ZnO}$ nanoparticles flowchart as shown in Fig 1 is derived from J. Hasnidawani et al. and M. Mustafa, O. Dalia's experimentations [6]-[7]. Three separate portions of 8.0 grams of zinc acetate dihydrate powder and 32,48 or 64 grams of sodium hydroxide pellets were added to their respective beakers, where the stirring was initiated simultaneously at room temperature. The visual observation was a clear coloured solution in all beakers. The zinc acetate dihydrate solutions (40 millilitre) were then mixed with the sodium hydroxide solutions ( 60 millilitre) while a continuous stirring rate was maintained at $\sim 450 \mathrm{rpm}$ and then increased to $\sim 500 \mathrm{rpm}$ once the entire content of the first beaker was mixed with the second one. An oil/gel-like layer formed on the surface of the solution once the mixing started.

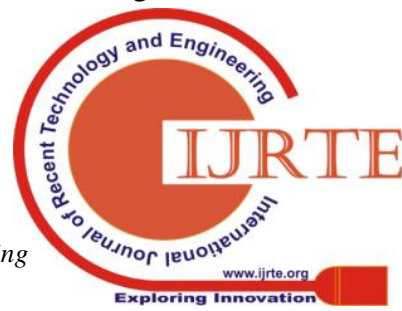


However, the layer disappeared within the mixture in a matter of few seconds.

Lastly, once the $\mathrm{Zn} / \mathrm{NaOH}$ mixture was ready, it was added (drop-wise) to the ethanol beaker under continuous stirring and visibly dispersed white precipitates formed instantly throughout the ethanol.

$$
\begin{gathered}
\left(\mathrm{Zn}\left(\mathrm{CH}_{3} \mathrm{COO}\right)_{2} 2 \mathrm{H}_{2} \mathrm{O}\right)+2 \mathrm{NaOH} \rightarrow \\
\mathrm{ZnO}+2 \mathrm{NaCH}_{3} \mathrm{COO}+\mathrm{H}_{2} \mathrm{O} \\
\mathrm{Zn}(\mathrm{OH})_{2}(\mathrm{gel})+2 \mathrm{H}_{2} \mathrm{O}= \\
\mathrm{Zn}^{2+}+2 \mathrm{OH}^{-}+2 \mathrm{H}_{2} \mathrm{O}=\left[\mathrm{Zn}(\mathrm{OH})_{4}\right]_{2} \\
{\left[\mathrm{Zn}(\mathrm{OH})_{4}\right]^{2-} \leftrightarrow \mathrm{ZnO}_{2}^{-2}+2 \mathrm{H}_{2} \mathrm{O}} \\
\mathrm{ZnO}_{2}^{-2}+2 \mathrm{H}_{2} \mathrm{O} \leftrightarrow \mathrm{ZnO}+2 \mathrm{OH}^{-}
\end{gathered}
$$

The above equations govern the formation of $\mathrm{ZnO}$ nanoparticles [6]-[7]. The process is complex and can be broken down into two stages: The $\mathrm{ZnO}$ nuclei generation followed by $\mathrm{ZnO}$ crystal growth, as explained by $\mathrm{M}$. Mustafa et al. [7]. The resultant dispersion of nanoparticles was then decanted, dried and separated into three portions followed by calcination at $250^{\circ} \mathrm{C}, 450^{\circ} \mathrm{C}$ and $650^{\circ} \mathrm{C}$ (Samples A1/B1, B2 and $\mathrm{B} 3$ respectively), respectively for 8 hours to create the

Less volumes of materials can be used to obtain $\mathrm{ZnO}$, as well [6], but for the purpose of creating multiple samples for performance analysis and destructive characterisation, the amounts of materials were increased accordingly.

\section{B. Colourimetric Analysis}

In preparation for the colourimetric analysis, the colouring reagent was prepared using EMSURE® $\mathrm{L}(+)$ - ascorbic acid (C6H8O6), ammonium molybdate tetrahydrate ((NH4)6Mo7O24.4H2O) (R\&M Chemicals), antimony potassium tartrate (R\&M Chemicals) $(\mathrm{K}(\mathrm{SbO}) \mathrm{C} 4 \mathrm{H} 4 \mathrm{O} 6)$ and sulphuric acid (H2SO4) (Sigma Aldrich). Furthermore, a arsenic concentration was also prepared from the previously described colouring reagent by adding 11 millilitre of deionised (DI) water and 0.25 millilitre of $1 \%$ hydrochloric acid (Sigma Aldrich) $\mathrm{HCl}$.

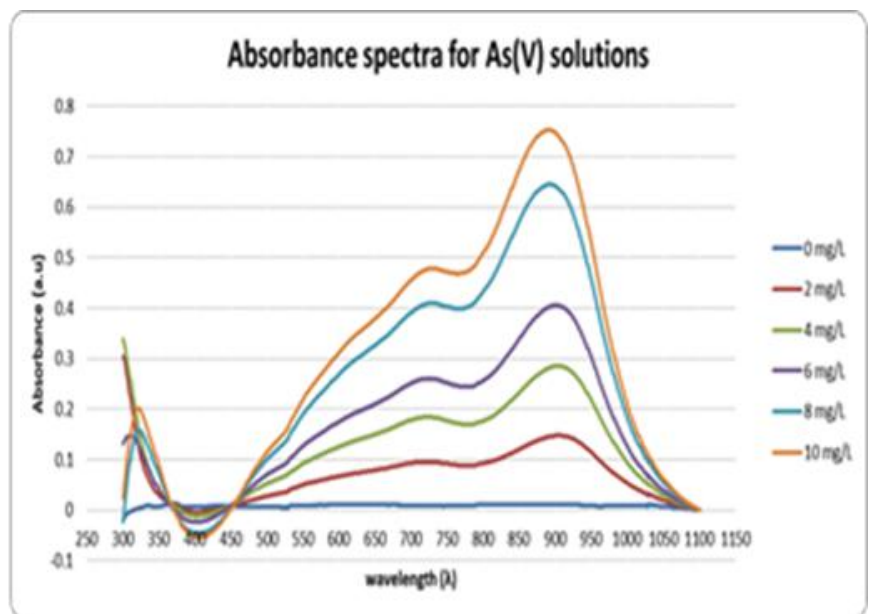

Fig 2. Absorbance peaks of calibrated samples with known $\operatorname{As}(V)$ concentrations. powdered samples. blank solution to be used as the reference point for zero

Results from the UV-Vis measurements showed that the six calibration samples $(\mathrm{As}(\mathrm{V})$ solutions with concentrations of $0,2,4,6,8$ and 10 milligram/Litre) reached light absorbance peaks at wavelength $\lambda=900$ nanometres as shown in Fig 2. The trend of increased light absorption with the increase of $\mathrm{As}(\mathrm{V})$ concentration at a designated wavelength is similar to that reported by $\mathrm{L}$. Wu et al. (2017) [8], where the colourimetric method was used to analyse the concentrations of $\mathrm{H} 2 \mathrm{O} 2$ in their research. The higher light absorption is due to the test sample generating a darker hue of blue colour with the increase of $\mathrm{As}(\mathrm{V})$ concentration within it, which results in absorbing more light, and less light passing through the solution.

Since different materials and elements react differently to specific wavelengths, and since the UV-Vis measures the test samples relative to a reference (blank), hence the graph may exhibit non-linear trends and even reversal in absorbance values, indicating that the reference sample absorbs more light than the test one. It could also be due to formation of moisture on the surface of the reference cuvette or a presence of a contaminant in it. In other cases the samples might have a luminance reaction to certain wavelengths, causing them to emit light, which is then detected by the UV-Vis and interpreted as more light making it through the sample without being absorbed.

It is also evident from Fig 2 that the absorbance vs. wavelength for the six calibrated samples showed the same trend with respect to the wavelength spectrum between 300 nanometre to 1100 nanometre.

Based on the absorbance values for the calibrated samples at $\lambda=900$ nanometre, a graph of absorbance vs. concentration was plotted as shown in Fig 3. The linear equation obtained through the linear regression method has a correlation coefficient (R2) value of 0.99 , which is close to unity. This indicates the outstanding accuracy of the calibration curve and that the linear equation generated is a good approximation of the data points.

\section{Calibration Curve}

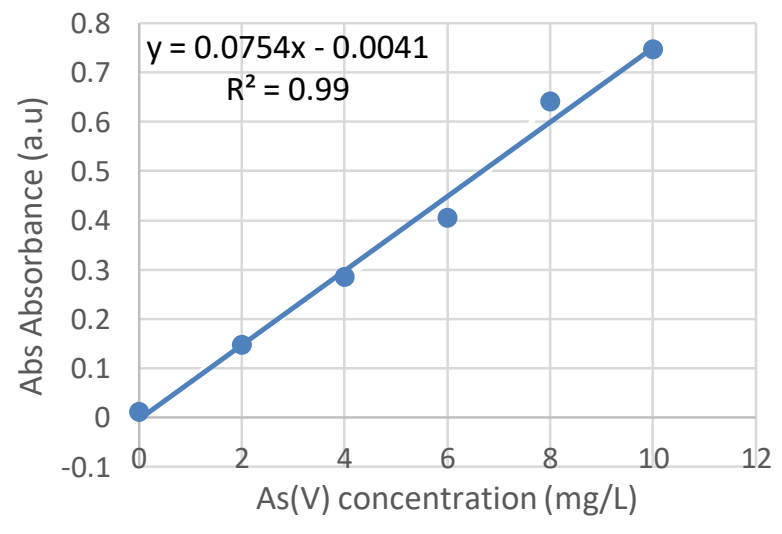

Fig 3. Calibration curve, linear equation and R-squared value. 
The adsorption capacity can be therefore be determined by the following equation:

$$
q=\frac{M_{i}-M_{f}}{m}
$$

Where $\mathrm{q}=$ adsorption capacity, $\mathrm{Mi}=$ initial mass of $\mathrm{As}(\mathrm{V})$, $\mathrm{Mf}=$ final mass of $\mathrm{As}(\mathrm{V})$ and $\mathrm{m}=$ mass of $\mathrm{ZnO}$ nanoparticles added to the As(V) solution.

Adsorption capacity (q) in equation 5 is found by substituting for (Mf) since the other parameters of the equation are constant throughout the measurements [9] [16]. The absorbance values obtained using the UV-Vis will be correlated to the linear equation to obtain the remaining $\mathrm{As}(\mathrm{V})$ concentration. From the remaining concentration, the Mf can be determined and thus the adsorption capacity, which will indicate how much of $\mathrm{As}(\mathrm{V})$ was successfully removed from the solution by every 1 gram of the $\mathrm{ZnO}$ nanoparticles.

\section{C. UV-Vis Testing}

The As(V) adsorption testing is as shown in Fig 4. The mixture is allowed 15 minutes of rest for the reaction between $\mathrm{As}(\mathrm{V})$ and the colouring reagent to take place and produce a blue-hued solution, which is then extracted into a disposable cuvette and its absorbance measured by a UV-Vis with reference to the blank sample.

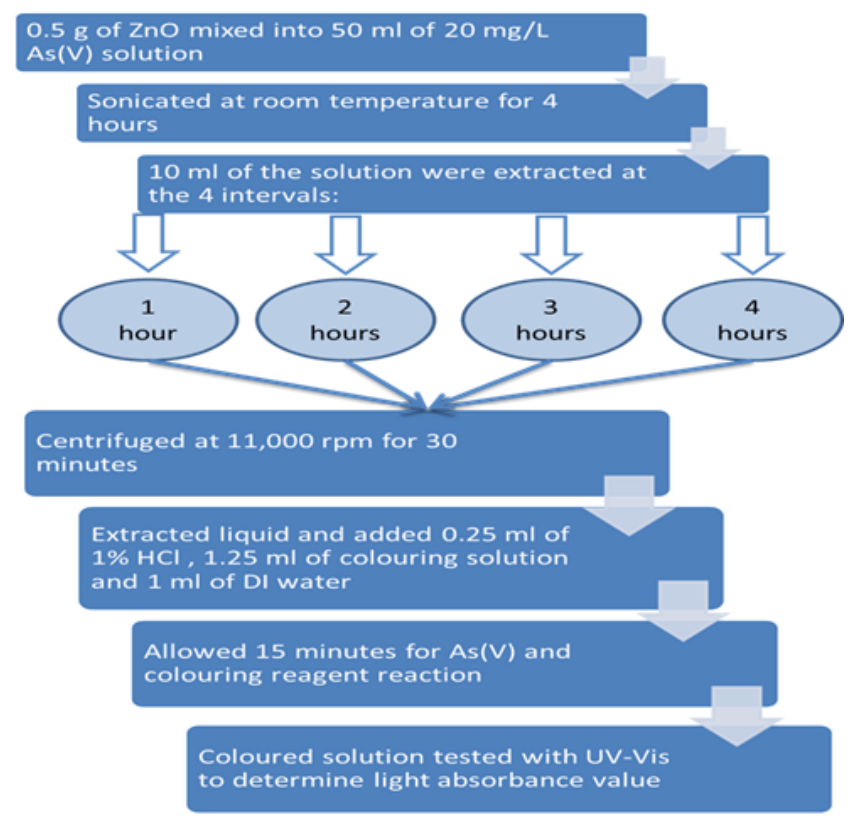

Fig 5. As(V) adsorption testing flowchart.

\section{RESULTS AND DISCUSSION}

\section{A. Explored Parameters}

$\mathrm{ZnO}$ nanoparticles were synthesised under two different parameters as described to explore their effect on the adsorption performance; Parameter A ( $\mathrm{Zn}: \mathrm{NaOH}$ Ratios) and Parameter B (Calcination Temperature). The synthesis process was successful in obtaining $\mathrm{ZnO}$ as proved by well-established characterisation techniques registered in the Joint Committee on Powder Diffraction Standards (JCPDS) and achieved by experimentation by M. Mustafa and O. Dalia's [7]. The average size data obtained from the nanoparticle size analyser "Nano S System" shows the presence of Z-average (d.nanometre) particles ranging from 1282 to 1544 nanometres, swaying the size more into the micrometre spectrum.

\section{B. B. X-Ray Diffraction Characterisation Results}

The synthesised $\mathrm{ZnO}$ nanopowder at various calcination temperatures using zinc acetate dihydrate as a precursor as described in previous sections was characterised and analysed for the purpose of heavy metals removal. The XRD patterns range from angles of $20^{\circ}-80^{\circ}$ of unit $2 \theta$. High and sharp peaks can be observed at $32^{\circ}$ which indicate the crystallinity orientation of $\mathrm{ZnO}$. The graph depicts a single-phase $\mathrm{ZnO}$ with clear diffraction peaks for each sample. The obtained XRD patterns follow the indexed hexagonal wurtzite $\mathrm{ZnO}$ [10] and match the JCPDS data No. 36-1451 for wurtzite $\mathrm{ZnO}$ as well as results obtained by Hasnidawani et al. [6] and Moazzen et al. [11] for their $\mathrm{ZnO}$ samples.

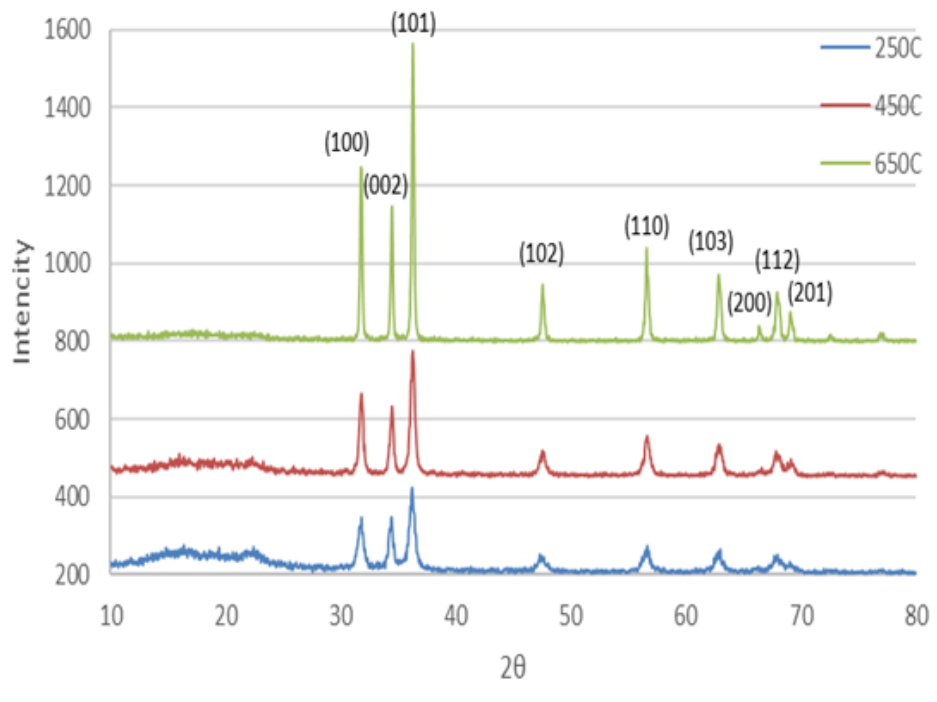

Fig 4. XRD profiles for the synthesised nanoparticles at different calcination temperatures.

Judging by the high intensity and narrow-width peaks of the XRD profiles (B1, B2, B3 peaks ascending in intensity respectively in Fig 5), the samples appear to be in micrometre size range rather than nanometre. This is because nanometre-sized particles would exhibit broader and shorter peaks [12]. In this scenario of higher calcination temperatures, the reaction is dictated by the nucleus formation. As the temperature is continuously rising, the rapid formation of the crystal nucleus causes the nuclear-aggregation phenomenon, resulting in aggregation of the crystal nucleus. An important factor that affects both the structure (crystallinity) and morphology of the powder is the rate of particle aggregation. This eventually results in a larger crystal size [13] [15].

As can be deduced from the XRD profiles, the crystal size and calcination temperature are directly proportional, which correlates to the data provided by Parra et al. (2014) [13].

In addition, nanoparticle size analyser "Nano S System" results confirmed the increase in average particles sizes with either increase of $\mathrm{NaOH}$ ratio or calcination temperature as seen in Table I. 
Table I. Nanoparticle size analyser results summary.

\begin{tabular}{|l|l|}
\hline & $\begin{array}{l}\text { Z-average particle } \\
\text { size diameter }(\mathrm{nm})\end{array}$ \\
\hline $\mathrm{A} 1 / \mathrm{B} 1\left(8: 32 \mid 250^{\circ} \mathrm{C}\right)$ & 1282 \\
\hline $\mathrm{A} 3\left(8: 64 \mid 250^{\circ} \mathrm{C}\right)$ & 1470 \\
\hline $\mathrm{B} 2\left(8: 32 \mid 450^{\circ} \mathrm{C}\right)$ & 1544 \\
\hline
\end{tabular}

The results of the nanoparticle size analyser represented in diameter give a clearer view of the increase in the particle sizes than the XRD profiles.

As described, the samples synthesised; A1/B1 (8:32 $\left.250^{\circ} \mathrm{C}\right), \mathrm{A} 2\left(8: 48 \mid 250^{\circ} \mathrm{C}\right), \mathrm{A} 3\left(8: 64 \mid 250^{\circ} \mathrm{C}\right), \mathrm{B} 2(8: 32 \mid$ $\left.450^{\circ} \mathrm{C}\right)$ and $\mathrm{B} 3\left(8: 32 \mid 650^{\circ} \mathrm{C}\right)$ suffered a significant increase in their average particle sizes. And it is noted from Table I that one-step increase in calcination temperature from B1 to B2 $(250-450)^{\circ} \mathrm{C}$ had more detrimental effect on the average size than a two-step increase in $\mathrm{NaOH}$ ratio from $\mathrm{A} 1$ to $\mathrm{A} 3$ (8:32 to $8: 64$ ), which proves that calcination temperatures do affect the process more significantly.

\section{Arsenic removal performance analysis}

Using the spectrometry techniques of UV-Vis and incorporating the colourimetric method provided an easy and inexpensive testing for $\mathrm{As}(\mathrm{V})$ removal performance. Fig 6 depicts the adsorption capacity (q) measured in milligram/gram vs. contact time between the As(V) solutions and the five synthesised $\mathrm{ZnO}$ samples during the varying four sonication intervals. On the other hand, Fig 7 shows the removal percentage of the $\mathrm{As}(\mathrm{V})$ ions from the solution against the contact time during the same sonication intervals. A general pattern emerges gradually as the time passes of increased absorbance capacity and removal percentage with increased contact time. The magnitudes of the adsorption capacity and removal percentage hardly change past the second-hour mark for each sample as the $\mathrm{ZnO}$ particles surface has reached saturated adsorption and either drop or increase lightly by the fourth hour.

At a time of 0 minutes, prior to the sonication process of the nanoparticle sample in the 20 milligram/Litre of As(v) solution, the adsorption capacity is taken to be zero as it is assumed that the adsorption process has not yet commenced within the solution. Also, at 0 minutes the concentration of the $\mathrm{As}(\mathrm{V})$ within the solution is maintained at the value of 20 milligram/Litre with no reduction in the concentration still, hence the zero values. The adsorption capacity and As(V) removal percentage for each sample at the four test time intervals are summarised in Table II.

The increase over time is due to both the increased contact time and sonication time, which results in more $\mathrm{As}(\mathrm{V})$ adsorption onto the surface of $\mathrm{ZnO}$ nanoparticles as the $\mathrm{ZnO}$ break down into smaller particles. However, as illustrated in Fig 8, heavier $\mathrm{ZnO}$ particles precipitated at the bottom of the beakers. Those heavier $\mathrm{ZnO}$ particles have a larger size and a lower surface to volume ratio that results in a lower adsorption surface. Meaning they would have a lower adsorption capacity and will not have the same performance as the smaller ones [14], which are more likely to be concentrated at the top of the beaker. This phenomenon explains the drop in adsorption capacity past the second-hour mark. The best performing sample with the highest yield and adsorption capacity was A1/B1 $\left(8: 32 \mid 250^{\circ} \mathrm{C}\right)$ followed by $\mathrm{A} 2\left(8: 48 \mid 250^{\circ} \mathrm{C}\right), \mathrm{A} 3\left(8: 64 \mid 250^{\circ} \mathrm{C}\right), \mathrm{B} 2\left(8: 32 \mid 450^{\circ} \mathrm{C}\right)$, and B3 $\left(8: 32 \mid 650^{\circ} \mathrm{C}\right)$, respectively. The maximum adsorption capacity of 1.9027 milligram/gram and $95.1392573 \%$ of
As(V) removed was achieved by sample A1, followed by A2, A3, B2 and B3 respectively. The highest peak for A1 (at 4 hours) is more than double that of B2 and the gap is even more between A1 to B3 as seen in Table II, which proves that the increased $\mathrm{NaOH}$ ratio during the synthesis first step process is detrimental to the adsorption performance of the particles.

With regards to parameter $\mathrm{A}$ ( $\mathrm{NaOH}$ concentration), the increase in concentration during the synthesis would degrade the adsorption performance as this variation in the synthesis process would alter the morphology of the produced $\mathrm{ZnO}$ crystals and result in larger crystal size with less surface-to-volume ratios as described by Moazzen et al. experiment [11].

Similarly, parameter B (calcination temperatures: 250, 450 and $650^{\circ}$ Centigrade) follows the trend of parameter $\mathrm{A}$; increasing the calcination temperature caused the adsorption performance to drop. The adsorption analysis showed that to obtain satisfactory results within this research, the upper threshold point of zinc acetate dihydrate : sodium hydroxide ratio to be used for the synthesis of $\mathrm{ZnO}$ is $0.911: 20 \mathrm{~mol}$ with removal percentage of $82.301 \%$ and adsorption capacity of 1.646 milligram/gram. As for the calcination temperature, at $250^{\circ} \mathrm{C}$, the sample exhibited exceptional As(V) removal percentage of $95.14 \%$ but less favourable results at higher calcination temperature.

It is thus concluded that higher sodium hydroxide ratios reduce the adsorption performance but higher calcination temperatures degrade the performance even more significantly. This is due to the significant increase in the particle size with calcination temperature as compared to the effect of $\mathrm{NaOH}$.

Lastly, larger particles are a two-edged sword. This research has established and confirmed that smaller particles have higher adsorption capacity and better performance against $\mathrm{As}(\mathrm{V})$. However, for the complete isolation of the $\mathrm{As}(\mathrm{V})$ sorbed $\mathrm{ZnO}$ NPs from the solution an additional step is required e.g. coagulation or filtration which both prefer larger particle sizes as it eases the treatment process.

\section{ADSORPTION CAPACITY VS. CONTACT TIME}

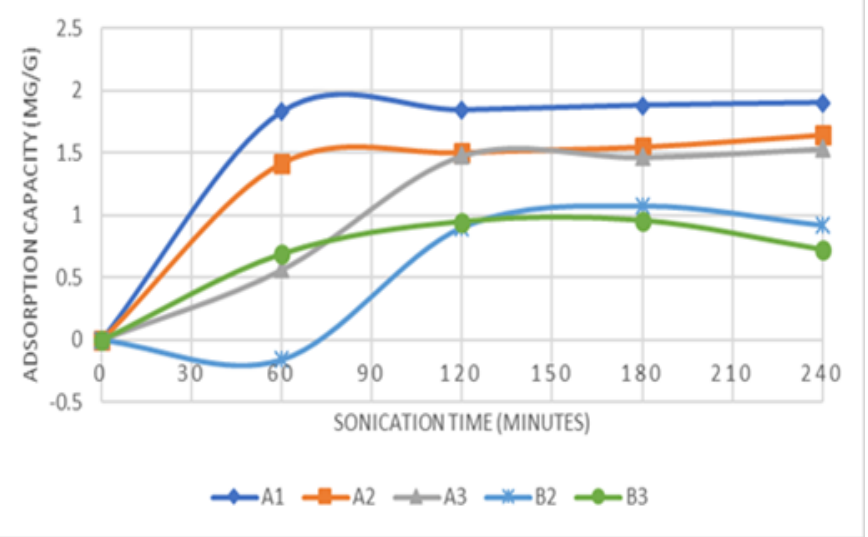

Fig 6. Adsorption capacity vs. sonication time for all samples. 


\section{\% REMOVAL OF AS(V) VS. CONTACT TIME}

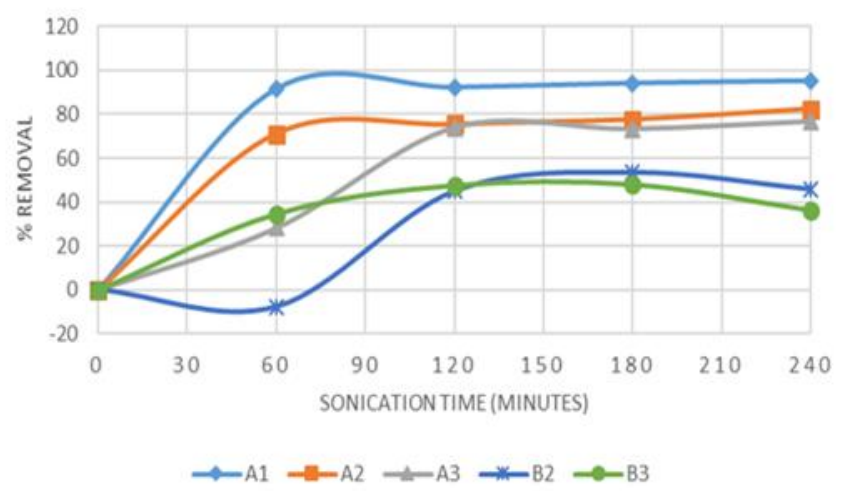

Fig 7. Removal percentage vs. sonication time for all samples.

Table II. Summary of each sample adsorption capacity and $\mathrm{As}(\mathrm{V})$ removal percentage.

\begin{tabular}{|c|c|c|c|}
\hline Sample & Time (minutes) & $q(\mathrm{mg} / \mathrm{g})$ & Removal \% \\
\hline \multirow{5}{*}{$\begin{array}{c}A 1(8: 32) \mid \\
\left(250^{\circ} \mathrm{C}\right)\end{array}$} & 0 & 0 & $0 \%$ \\
\hline & 60 & 1.82904509 & $91.4522546 \%$ \\
\hline & 120 & 1.84376658 & $92.1883289 \%$ \\
\hline & 180 & 1.88156499 & $94.0782493 \%$ \\
\hline & 240 & 1.90278515 & $95.1392573 \%$ \\
\hline \multirow{5}{*}{$\begin{array}{c}A 2(8: 48) \mid \\
\left(250^{\circ} \mathrm{C}\right)\end{array}$} & 0 & 0 & $0 \%$ \\
\hline & 60 & 1.419761 & $70.9880637 \%$ \\
\hline & 120 & 1.504775 & $75.2387268 \%$ \\
\hline & 180 & 1.549337 & $77.4668435 \%$ \\
\hline & 240 & 1.646021 & $82.301061 \%$ \\
\hline \multirow{5}{*}{$\begin{array}{c}A 3(8: 64) \mid \\
\left(250^{\circ} \mathrm{C}\right)\end{array}$} & 0 & 0 & $0 \%$ \\
\hline & 60 & 0.564456 & $28.2228117 \%$ \\
\hline & 120 & 1.478382 & $73.9190981 \%$ \\
\hline & 180 & 1.466976 & $73.3488064 \%$ \\
\hline & 240 & 1.535809 & $76.7904509 \%$ \\
\hline \multirow{5}{*}{$\begin{array}{c}\text { B2 (8:32) I } \\
\left(450^{\circ} \mathrm{C}\right)\end{array}$} & 0 & 0 & $0 \%$ \\
\hline & 60 & -0.1561 & $-7.80503979 \%$ \\
\hline & 120 & 0.898011 & $44.9005305 \%$ \\
\hline & 180 & 1.069098 & $53.4549072 \%$ \\
\hline & 240 & 0.915517 & $45.7758621 \%$ \\
\hline \multirow{5}{*}{$\begin{array}{c}\text { B3 }(8: 32) \mid \\
\left(650^{\circ} \mathrm{C}\right)\end{array}$} & 0 & 0 & $0 \%$ \\
\hline & 60 & 0.688727 & $34.4363395 \%$ \\
\hline & 120 & 0.947613 & $47.3806366 \%$ \\
\hline & 180 & 0.956101 & $47.8050398 \%$ \\
\hline & 240 & 0.72321 & $36.1604775 \%$ \\
\hline
\end{tabular}

$\mathrm{ZnO}$ particles tend to agglomerate, thus to produce smaller $\mathrm{ZnO}$ particles (larger surface area) for improved adsorption performance using the discussed methodology, three workarounds are suggested; lower ratios of $\mathrm{NaOH}$, lower calcination temperatures and specialised grinding and milling equipment to break apart the agglomerated particles. Alternatively, use a suitable coating to separate the $\mathrm{ZnO}$ nanoparticles and other routes for $\mathrm{ZnO}$ synthesis may be explored as well.

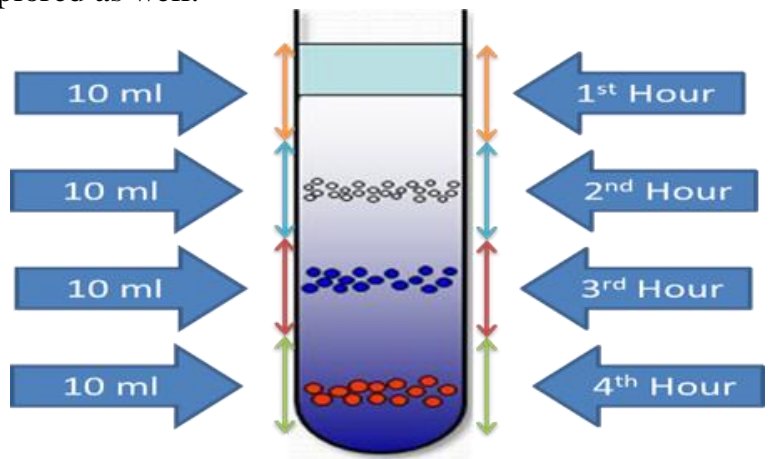

Fig 8. Segments of the As(V) solutions as extracted through several intervals.
In general, the larger the particle, the smaller the surface area to volume ratio and evidently lower adsorption capacity and performance.

\section{IV. CONCLUSION}

$\mathrm{ZnO}$ nanoparticles were synthesised successfully under two varying parameters; different $\mathrm{Zn}: \mathrm{NaOH}$ ratios of 8:32 grams, 8:48 grams and 8:64 grams and different calcination temperatures of $250^{\circ}, 450^{\circ}$ and $650^{\circ}$ Centigrade using the sol-gel method.

With the assistance of the X-Ray Diffraction characterisation, a conclusion was drawn that higher temperature promotes the $\mathrm{ZnO}$ crystal's growth and enhances their crystallinity. The crystal core formation process was accelerated rapidly within a short period of time. This is a result of the increase in the supersaturation of the products of the chemical reactions, which in itself is due to the increased speed of the nucleation rate, which is a result of the increased calcination temperature [13][15].

Ultimately, the adsorption performance was evaluated based on predefined and prepared measuring spectra of known concentrations of $\mathrm{As}(\mathrm{V})$ solutions. The light absorption peaks of these concentrations at wavelength $\lambda=$ 900 nanometres were measured by the UV-Vis and used to plot a calibration curve and construct a linear equation that will correlate the actual testing samples' light absorption values to the calibration curve and subsequently the measuring spectra. Once the data was evaluated it was possible to quantify the adsorption capacity (q) and the percentage of $\mathrm{As}(\mathrm{V})$ removed from the solution. As expected and explained, the removal performance deteriorated with the increase in either calcination temperature and/or $\mathrm{NaOH}$ ratio due to the increased average particle size.

Finally, although the synthesis parameters of ZnO NPs for the purpose of removal of $\mathrm{As}(\mathrm{V})$ from water is not yet optimised nor gone through sophisticated processes of refining, it showed great potential for $\mathrm{As}(\mathrm{V})$ adsorption. Future developments and applications in this field can be achieved through the optimisation path supported by the consistency of the data reported through this research.

\section{ACKNOWLEDGMENT}

Authors are grateful to Multimedia University for allowing the usage of the facilities and equipment. Thanks are due to Assoc. Prof. Chan KahYoong for providing the funds for XRD characterisation.

\section{REFERENCES}

1. P. Leonard, S. Hearty, J. Brennan, L. Dunne, J. Quinn, T. Chakraborty and R. O'Kennedy, "Advances in biosensors for detection of pathogens in food and water", Enzyme and Microbial Technology, vol. 32, no. 1, pp. 3-13, 2003.

2. S. Wang and C. Mulligan, "Occurrence of arsenic contamination in Canada: Sources, behavior and distribution", Science of The Total Environment, vol. 366, no. 2-3, pp. 701-721, 2006.

3. "Mining Information Institute. Mineral Photos - Arsenic.Mineral Photos", 2012. [Online]. Available: http://www.mii.org/Minerals/photoarsenic.html. [Accessed: 11- Jul2017]. 
4. P. Tchounwou, A. Patlolla and J. Centeno, "Carcinogenic and Systemic Health Effects Associated with Arsenic Exposure - A Critical Review", Toxicologic Pathology, vol. 31, no. 6, pp. 575-588, 2003.

5. H. Canada, "Guidelines for Canadian Drinking Water Quality: Guideline Technical Document - Arsenic - Canada.ca", Hc-sc.gc.ca, 2017.$$
\text { [Online]. }
$$
Available: http://www.hc-sc.gc.ca/ewh-semt/pubs/water-eau/arsenic/index-eng.p hp. [Accessed: 11- Jul- 2017].

6. J. Hasnidawani, H. Azlina, H. Norita, N. Bonnia, S. Ratim and E. Ali, "Synthesis of ZnO Nanostructures Using Sol-Gel Method", Procedia Chemistry, vol. 19, pp. 211-216, 2016.

7. M. Mustafa, O. Dalia, "Synthesis and Characterization of Zinc Oxide Nanoparticles using Zinc Acetate Dihydrate and Sodium Hydroxide", Journal of Nanoscience and Nanoengineering. 1. 248-251, 2015.

8. L. Wu, W. Yin, X. Tan, P. Wang, F. Ding, H. Zhang, B. Wang, W. Zhang and $\mathrm{H}$. Han, "Direct reduction of $\mathrm{HAuCl} 4$ for the visual detection of intracellular hydrogen peroxide based on $\mathrm{Au}-\mathrm{Pt} / \mathrm{SiO} 2$ nanospheres", Sensors and Actuators B: Chemical, vol. 248, pp. 367-373, 2017

9. Lo, S. F., Wang, S. Y., Tsai, M. J., \& Lin, L. D. (2012). Adsorption capacity and removal efficiency of heavy metal ions by Moso and Ma bamboo activated carbons. Chemical Engineering Research and Design, 90(9), 1397-1406.

10. Devaraj, N. K., Han, T. C., Low, P. L., Ong, B. H., \& Sin, Y. K. (2014). Synthesis and characterisation of zinc oxide nanoparticles for thermoelectric application. Materials Research Innovations, 18(sup6), S6-350.

11. M. Moghri Moazzen, S. Borghei and F. Taleshi, "Change in the morphology of $\mathrm{ZnO}$ nanoparticles upon changing the reactant concentration", Applied Nanoscience, vol. 3, no. 4, pp. 295-302, 2012.

12. P. Muhammed Shafi and A. Chandra Bose, "Impact of crystalline defects and size on X-ray line broadening: A phenomenological approach for tetragonal $\mathrm{SnO} 2$ nanocrystals", AIP Advances, vol. 5, no. 5, p. $057137,2015$.

13. M. Parra and F. Haque, "Aqueous chemical route synthesis and the effect of calcination temperature on the structural and optical properties of $\mathrm{ZnO}$ nanoparticles", Journal of Materials Research and Technology, vol. 3, no. 4, pp. 363-369, 2014.

14. M. Hua, S. Zhang, B. Pan, W. Zhang, L. Lv and Q. Zhang, "Heavy metal removal from water/wastewater by nanosized metal oxides: A review", Journal of Hazardous Materials, vol. 211-212, pp. 317-331, 2012.

15. V. Venu Gopal and S. Kamila, "Effect of temperature on the morphology of $\mathrm{ZnO}$ nanoparticles: a comparative study", Applied Nanoscience, vol. 7, no. 3-4, pp. 75-82, 2017.

16. Devaraj, N. K., Elghazali, S. R., Ganapathe, L. S., Mukter-Uz-Zaman, A. AND Wong, H. Y., "As(V) Adsorption Kinetics of Humic Acid-Coated Magnetite Particles", Applied Mechanics and Materials, 892, pp.72-78.

\section{AUTHORS PROFILE}

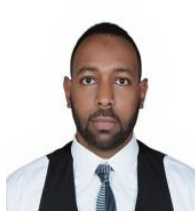

Mr. Merghani Hassan is an Electronics engineer working for an international company in planning, management, implementation and delivering of multimillion projects and has established a reputation for himself in the industry. He is assigned major roles for the delivery of governmental-level and military-grade projects through a whole country. He graduated with a B.Eng.(Hons) Electronics degree majoring in Nanotechnology from Multimedia University (MMU) in 2018. His memberships include IEEE and SCE.

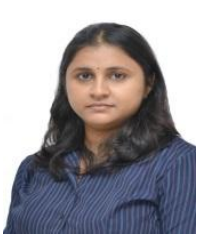

Nisha Kumari Devaraj is a lecturer at the Faculty of Engineering, Multimedia University (MMU). She graduated with a B.Eng.(Hons) Electronics degree from MMU in 2005 and and Master of Engineering Science (M.Eng.Sc) in 2010, also from MMU. She has published 5 journal articles as main author and 3 as co-author, 2 conference proceedings and 1 book chapter. Throughout her tenure at MMU as a student and also a lecturer, she has been a recipient of a bronze medal at the 20th International Invention, Innovation and Technology Exhibition (ITEX'09), letters of merit from the president and vice-president of MMU for her teaching evaluation scores, book award for her graduation, as well the Dean's awards for several trimesters of her undergraduate studies. Most recently, she obtained the bronze award for her project: "Nanostructured Magnetic Materials for Heavy Metal Ion Detection" at the RICES2018 held in MMU.

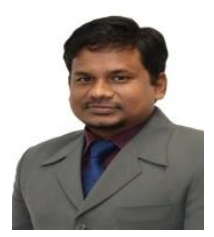

Dr. A S M Mukter Uz Zaman completed his BSc in Computer Science and Engineering department of Khulna University of Engineering and Technology, KUET, Bangladesh in 2003. In 2008 Dr. Mukter awarded his Master of Engineering Science degree from the Faculty of Engineering, Multimedia University, Malaysia. In 2013, Dr. Mukter awarded the Doctor of Philosophy $(\mathrm{PhD})$ degree in Electrical, Electronic and Systems Engineering from Universiti Kebangsaan Malaysia (The National University of Malaysia).

Dr. Mukter started his career at Arafat Information Technology and Electronics limited as an Integrated System Designer in 2003 and worked until 2006. From 2008-2012 Dr. Mukter worked as a researcher in MIMOS Berhad, Malaysia. Dr. Mukter Joined in Multimedia University as an academician back to 2013 and he is continuing till now. In 2017 one of Dr. Mukters breakthrough research invention gained enormous interest in the research community. In order to bring the technology out to the market Dr. Mukter founded a Spin-off company under Multimedia University's entrepreneur development scheme. Besides an academician of Multimedia University, Dr Mukter working as a chief technical officer (CTO) of the spin-off company named PolTechCare Sdn Bhd from 2017.

Dr. Mukter's core expertize is in the area of micro nano-electronic devices and systems. Dr. Mukter's expertise in the area of mico-nanoelectronic sensors and system integrated with cloud computing is well recognized in the research communities. Dr. Mukter is the inventor of more than twenty (20 patented technologies) and many of this technologies are currently solving real industrial problems. Dr. Mukter is also an expert in the Internet-of-Thing (IoT) based system engineering where his core focus is on Engineering design and development of sensor and sensing based system. Fabrication and characterization of advance particle that could be used in the sensing system is also my core area of expertise.

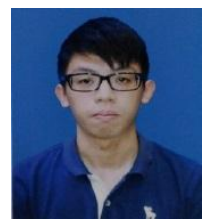

Mr. Wei Wen Wong obtained his Bachelor's honours degree in electronics engineering at Multimedia University, Malaysia, in 2016. In his honours research project, he studied the arsenic removal capability of magnetic core-shell inorganic nanoparticles for advanced water treatment applications. His honours project resulted in 1 patent, 1 journal paper, 2 conference publications, and was awarded with the Silver medal at the 27th International Invention \& Innovation Exhibition (ITEX) held at Kuala Lumpur, Malaysia, in 2016. He was awarded with the "Best Nanotechnology Engineering Student" prize in the university's 2016 convocation ceremony. He was a summer research student at the European Organization for Nuclear Research (CERN), working on improving signal multiplexing efficiency in the Compact Muon Solenoid (CMS) detector of the Large Hadron Collider. From 2016 to 2018, he worked as a failure analysis engineer in Cypress Semiconductor at Penang, Malaysia. In 2018, he joined the Electronic Materials Engineering department at The Australian National University as a PhD student. His $\mathrm{PhD}$ research is on the selective area epitaxial (SAE) growth of III-V micro-ring structures on Silicon substrates for integrated photonics applications. $\mathrm{He}$ is a Graduate Engineer registered under the Board of Engineers Malaysia (BEM) and a graduate student member of IEEE. 